\title{
The effect of social exclusion on consumer preference for anthropomorphized brands 2 s
}

\author{
Rocky Peng Chen ${ }^{a, *}$, Echo Wen Wan ${ }^{b}$, Eric Levy ${ }^{c}$ \\ ${ }^{a}$ School of Business, Hong Kong Baptist University, Hong Kong \\ ${ }^{\mathrm{b}}$ Faculty of Business and Economics, University of Hong Kong, Hong Kong \\ ${ }^{\mathrm{c}}$ Judge Business School, University of Cambridge, United Kingdom
}

Accepted by Cornelia Pechmann and Amna Kirmani, Editors

Received 14 March 2014; received in revised form 9 May 2016; accepted 19 May 2016 Available online $\mathrm{xxxx}$

\begin{abstract}
Prior research has mainly examined the effect of social exclusion on individuals' interactions with other people or on their product choices as an instrument to facilitate interpersonal connection. The current research takes a novel perspective by proposing that socially excluded consumers would be more motivated to establish a relationship with a brand (rather than using the brand to socially connect with other people) when the brand exhibits human-like features. Based on this premise, we predict and find support in three studies that socially excluded consumers, compared with non-excluded consumers, exhibit greater preference for anthropomorphized brands (studies 1-3). This effect is mediated by consumers' need for social affiliation and is moderated by the opportunity for social connection with other people (study 2). Furthermore, socially excluded consumers differ in the types of relationships they would like to build with anthropomorphized brands, depending on their attributions about the exclusion. Specifically, consumers who blame themselves (others) for being socially excluded show greater preference for anthropomorphized partner (fling) brands (study 3).
\end{abstract}

(C) 2016 Society for Consumer Psychology. Published by Elsevier Inc. All rights reserved.

Keywords: Social exclusion; Anthropomorphism; Consumer preference; Social affiliation

Social exclusion is a pervasive experience in consumers' lives. People often experience incidents of being rejected or excluded in their relationships with family members, friends, colleagues, and acquaintances (Baumeister, DeWall, Ciarocco, \& Twenge, 2005; Williams, 2007). Because social exclusion thwarts the fundamental human need to belong, it can have significant psychological and behavioral consequences (Maner, DeWall, Baumeister, \&

\footnotetext{
is The first two authors share equal authorship. This research is supported by a Hong Kong SAR research grant (HKU 792613) awarded to the second author and a University of Cambridge Judge Business School Director's Grant (SG13-19) awarded to the third author.

* Corresponding author.

E-mail addresses: rockychen@hkbu.edu.hk (R.P. Chen), ewan@business.hku.hk (E.W. Wan), E.Levy@jbs.cam.ac.uk (E. Levy).
}

Schaller, 2007; Williams, 2007). Scholarly work has largely examined how socially excluded individuals might behave in interpersonal relationships, such as being more friendly or aggressive toward other people (Maner et al., 2007; Twenge, Baumeister, Tice, \& Stucke, 2001). Recently, consumer researchers have begun to investigate the impact of social exclusion on consumers' judgments and choice of products and brands. This line of research mainly focuses on how socially excluded individuals choose products so as to signal their intention and interest in building social connections with desired persons or groups (Mead, Baumeister, Stillman, Rawn, \& Vohs, 2011; Wan, Xu, \& Ding, 2014).

However, sometimes products can serve as more than just an instrument or medium for bonding with other people. Research on branding has suggested that products themselves can be the targets 
for relationship building, and that consumers can establish relationships with products or brands in similar ways to which they form interpersonal relationships (Fournier, 1998). Despite the large body of research that examines the behavioral consequences of social exclusion in the interpersonal domain, and the recent work in the consumption domain, it remains unclear how social exclusion might systematically influence consumers' brand preferences as a function of their motivation to affiliate directly with brands, rather than using brands as a tool to affiliate with other people. The current research attempts to address this issue.

Specifically, we examine how the experience of social exclusion influences consumer preference for brands that are anthropomorphized. Anthropomorphism, defined as imbuing the behavior of nonhuman agents with humanlike characteristics, motivations, intentions, or emotions (Epley, Waytz, \& Cacioppo, 2007), is often used in marketing communications that encourage consumers to see human characteristics in brands (Aggarwal \& McGill, 2007; Landwehr, McGill, \& Herrmann, 2011). For example, a brand may have a human-like mascot (e.g., the M\&M's guy), human-like cues within the logo (e.g., Pepsi's revamped logo similar to a smiling face), or be depicted in first person language and/or with human-like motion (e.g., I am coming to you). Because anthropomorphism allows consumers to see human-like characteristics in non-human objects, presenting products in an anthropomorphic manner can increase the chance of this product being viewed as a possible social affiliation partner. Therefore, we propose that socially excluded consumers, relative to non-excluded consumers, will prefer an anthropomorphized brand and that this effect is driven by consumers' need for social affiliation. To advance our understanding of socially excluded consumers' relationship building with anthropomorphized brands, we draw on attribution theory (Weiner, 1985) and suggest that excluded consumers differ in their preference for anthropomorphized brands with different brand roles in the relationship, depending on consumers' attribution of the social exclusion experience. Next we review the theoretical background, develop the hypotheses, and report three experiments that test our propositions.

\section{Theoretical background and current studies}

\section{Behavioral consequences of social exclusion}

Psychology research shows that individuals seek alternative means to satisfy a particular need when they feel that a specific need is deprived (Gardner, Pickett, Jefferis, \& Knowles, 2005). The experience of social exclusion signals that one's need to belong is not satisfied and thus motivates the person to attend to social cues suggesting opportunities for social reconnection and relationship building (Gardner et al., 2005). Consistent with this view, prior research has found that excluded individuals, compared with included individuals, paid greater attention to smiling faces (DeWall, Maner, \& Rouby, 2009), were more interested in making new friends, had greater desire to work with others, assigned greater rewards to new interaction partners (Maner et al., 2007), and were more likely to conform to others' opinions (Williams, Cheung, \& Choi, 2000). Recent work in marketing shows that consumers may adjust their spending patterns and product choices for the purpose of affiliating with others after experiencing social exclusion. For example, Mead et al. (2011) showed that socially excluded participants, in relation to non-excluded participants, were willing to spend more money on products that were symbolic of group membership, and were more likely to tailor their consumption preference to be consistent with those of their interaction partners.

Existing research on social exclusion has primarily examined how exclusion influences individuals' behaviors when they are given an opportunity for establishing affiliation with other people. One could affiliate through social interaction (e.g., showing increased interest in meeting new partners), or through consumption activities (e.g., conforming to a potential partner's product choices). However, consumers can also seek to establish relationships with brands in similar ways to relationship-building with people (Fournier, 1998). In the current research we propose that experiencing social exclusion would motivate consumers to seek affiliation directly with brands when the brands are presented in an anthropomorphic manner.

\section{Anthropomorphism in marketing communications}

Marketers often imbue brands with human-like characteristics (Epley et al., 2007) in marketing communications and seem to believe such a strategy should generally enhance positive responses to their brands. However, recent research suggests that how consumers respond to anthropomorphized brands may be more complex and dynamic than is typically assumed, and that consumers' responses may depend on their chronic or momentary motivations (Aggarwal \& McGill, 2012). For example, previous research suggests that one major motivation for people to anthropomorphize is the desire for social affiliation (Epley, Akalis, Waytz, \& Cacioppo, 2008). They may even wish to affiliate with non-human agents, such as pets, as if they were interacting with other human beings. Owning a pet has been found to help buffer the elderly from stressful life events, in a similar fashion to receiving social support from other people or groups (Siegel, 1990). In the current research, we examine how consumers' motives for social affiliation influence their responses to anthropomorphized brands. As discussed earlier, experiencing social exclusion increases individuals' motivation to pursue social reconnection and increases their sensitivity to cues that imply opportunities for acquiring new social relationships (DeWall et al., 2009; Williams et al., 2000). In a consumption context, brands presented in an anthropomorphized form can potentially become a target with which consumers can build social relationships. As a consequence, social exclusion is expected to increase consumers' preference for anthropomorphized brands, because these brands can help fulfill socially excluded consumers' needs for social affiliation. Formally, we put forth the following hypotheses: 
H1. Socially excluded consumers, relative to socially included consumers, would exhibit a greater preference for anthropomorphized brands (vs. non-anthropomorphized brands).

H2. Socially excluded consumers, relative to socially included consumers, would have stronger need for social affiliation, which would mediate the interactive effect of social exclusion and anthropomorphism on brand preference.

If social exclusion enhances preference for anthropomorphized brand because excluded (vs. included) consumers have stronger desire for social affiliation, then providing consumers with the opportunity to build social relationships with other people before their exposure to an anthropomorphized brand would fulfill the affiliation need and thus reduce these consumers' desire to affiliate with the anthropomorphized brand. Therefore, we hypothesize that:

H3. Socially excluded consumers' preference for anthropomorphized brands would be attenuated when they affiliate with other people before being exposed to the anthropomorphized brand.

Attribution of social exclusion and relationship-building with anthropomorphized brands

Although socially excluded consumers are expected to have a stronger need to build social relationships with anthropomorphized brands, they may differ in the desired type of relationship with the brand. Fournier (1998) proposes that brands can be seen as similar to human beings, and can take different roles in their relationships with consumers, such as a partner or a fling. As described in Fournier's (1998) typology of consumer-brand relationships, partner refers to a long-term union that is high in trust. It involves a commitment to stay together despite adverse circumstances. In contrast, fling is a temporary relationship. It is characterized by short-term engagements without commitment and reciprocity demands. In general, an anthropomorphized partner brand offers a long-term and committed relationship whereas an anthropomorphized fling brand offers a low-commitment relationship with short-term rewards. The current research proposes that socially excluded consumers differ in the types of relationships they would like to build with anthropomorphized brands, depending on the causal attributions that consumers make about why they were socially excluded.

When consumers experience social exclusion, they feel threatened while simultaneously seeking to understand the reason why they were socially excluded (Williams, 2007). Attribution theory (Weiner, 1985) proposes that the inferences that people make about the causes of events and behavior can be classed as internal or external. Internal attribution refers to characteristics of the target person, such as the person's ability and personality. External attribution, conversely, involves factors that are unrelated to the target person, such as the environment and other people involved in the event. Attributing an event to the self vs. other people can lead to different psychological consequences (Rotter, 1966). For example, negative outcomes with internal attribution lower self-esteem, whereas those with attribution to other people do not influence the self-view (Weiner, 1985). After being socially excluded, consumers can make either an internal attribution that they were excluded because of their own personalities and behaviors (i.e., self-blame) or an external attribution that the exclusion was due to bad intentions of the people around them (i.e., other-blame). When socially excluded consumers attribute the reason to self, they would form a negative view toward self, which leads them to question whether they are worthy of others' love and acceptance (Bartholomew \& Horowitz, 1991). The feelings of uncertainty in a new relationship and a fear of abandonment by others motivate them to seek a long-term partner that commits to the relationship (Swaminathan, Stilley, \& Ahluwalia, 2009). In contrast, excluded consumers who blame others form a negative view toward others. As a consequence, they are reluctant to trust that other people would be reliable in long-term relationships, and would therefore want to avoid intimacy in relationships (Swaminathan et al., 2009). However, these other-blaming excluded consumers still have the heightened motivation to satisfy the fundamental need of belongingness, and they are still eager to seek for new relationships. For other-blaming excluded consumers, instead of shunning social contact altogether, they tend to prefer less stable relationships with short-term rewards (Bartholomew \& Horowitz, 1991; Collins \& Read, 1990). Such short-term relationships can allow socially excluded consumers to compensate for the loss of belongingness without being involved in a long-term and committed relationship. This prediction is consistent with prior research showing that attachment styles related to having negative views of others, such as a dismissive attachment style and a fearful attachment style, were consistently associated with high levels of desire for short-term relationships (Schmitt, 2005).

Prior research has shown that consumers apply interpersonal social norms in their interactions with anthropomorphized brands (Aggarwal \& McGill, 2012). We thus expect that socially excluded consumers' differential preferences for new relationship will also apply to their interactions with anthropomorphized brands. Specifically, excluded consumers who blame themselves would form a negative view towards self. For these consumers, a partner brand that offers a long-term relationship with a commitment would be seen as a preferred target for building connections. In contrast, socially excluded consumers who blame others would form a negative view towards others. For these consumers, a partner brand that claims to offer a long-term and intimate relationship may not appeal to them. Instead, a fling brand that offers a low-commitment relationship with short-term rewards would be more appealing. Formally, we put forth the following hypothesis:

H4. Attributing the reason for being socially excluded to self (other) would increase socially excluded consumers' preference for partner (fling) brands.

Three experiments test our hypotheses. Study 1 examines the basic prediction (H1) and shows how the state of social exclusion versus inclusion influences consumers' preference for a real brand in an anthropomorphic form. Study 2 replicates 
the findings of study 1 and further reveals the mechanism using both mediation and moderation approaches (H2 and H3). Study 3 tests how self-attribution versus other-attribution influences excluded consumers' preference for partner brands versus fling brands (H4). Consumers' preference is measured using real choice behavior, attitudes, and purchase intentions.

\section{Study 1}

Study 1 tests the basic hypothesis that social exclusion would increase consumers' preference for anthropomorphized brands. This study involves a real brand of candy and a real choice between the focal candy and a non-anthropomorphized alternative brand. We predicted that socially excluded participants would prefer the focal brand when it is anthropomorphized versus when it is thought of as an object.

\section{Methods and procedure}

One hundred and eighteen students (41\% male) from a major university in United Kingdom participated in this experiment in return for monetary compensation. They were randomly assigned to a 2 (social exclusion: exclusion vs. inclusion) $\times 2$ (anthropomorphism: yes vs. no) between-subjects design.

\section{Manipulation of social exclusion}

Participants first performed a Cyberball game (Williams et al., 2000; Williams \& Jarvis, 2006) that has been widely used to manipulate social exclusion versus social inclusion. In this game, participants were asked to practice their mental visualization skills in a ball-tossing game with two other participants connected on the internet. Each player was asked to mentally visualize the players, the environment, the weather and so on, while clicking the icons on the computer screen to virtually catch and throw a ball. Unbeknownst to the participants, the actions of the other two players were actually preset by the computer program. Participants in the inclusion condition received one-third of the ball tosses, whereas those in the exclusion condition received the ball substantially less: they received only two tosses at the beginning of the game and no longer received any tosses in the remaining game. Excluded participants just watched the other two players tossing the ball to each other in the following 30-50 throws. When the ball-tossing game ended, participants responded to three manipulation check questions that asked the extent to which they felt ignored, rejected, and like an outsider when they were playing the ball game on seven-point scales $(1=$ not at all; $7=$ very much).

\section{Manipulation of anthropomorphism}

Next, participants were introduced to a seemingly unrelated consumer survey that asked their opinions about M\&M's candy. To manipulate anthropomorphism, we adopted the procedure used in Aggarwal and McGill (2012) which instructed the participants to think of the M\&M's candy as either a human being or simply an object. As a manipulation check for anthropomorphism, participants then answered two questions adapted from Kim and McGill (2011): "The brand feels like a person"; "It seems the brand has free will" ( 1 = strongly disagree; 9 = strongly agree).

Consumer preference measures: brand attitude and real choice After providing their thoughts about M\&M's candy, participants answered three questions to indicate their attitudes towards the brand: How much do you like M\&M's candy ( $1=$ dislike; $9=$ like)? How good is M\&M's candy $(1=$ bad; $9=$ good $)$ ? What's your opinion about M\&M's candy $(1=$ negative; $9=$ positive)? Finally, we administered a real choice task as an additional measure of participants' brand preference. Specifically, participants were told that in addition to the cash payment they would be receiving for their participation, they could also choose a pack of candy as an additional reward and would receive the chosen candy upon completing the study. They were presented with two candy options: M\&M's or Skittles. M\&M's was either anthropomorphized or not, depending on the experimental condition, while Skittles was non-anthropomorphized in all the conditions because participants had not received any anthropomorphic information about this brand. A pretest utilizing participants of similar backgrounds confirmed that these two candies were perceived to be similar in terms of price, physical appearance, taste, and popularity.

\section{Results and discussion}

\section{Manipulation checks}

We first averaged responses to the three manipulation check questions for social exclusion to form an exclusion score $(\alpha=.94)$. A 2 (social exclusion: exclusion vs. inclusion) $\times 2$ (anthropomorphism: yes vs. no) ANOVA on this score revealed that participants in the exclusion condition $(M=5.19)$ felt more excluded than those in the inclusion condition $(M=1.99$; $F(1,114)=178.45, p<.001)$, confirming the success of our social exclusion manipulation. No other effects were significant $(p \mathrm{~s}>.10)$. We also formed an anthropomorphism score $(r=.81)$ and submitted it to the $2 \times 2$ ANOVA. Validating our manipulation, participants in the anthropomorphism condition perceived the candy to be more humanized $(M=4.15)$ than those in the non-anthropomorphism condition $(M=2.44 ; F(1,114)=$ $18.65, p<.001)$. No other effects were significant $(p>.10)$.

\section{Consumer preference: brand attitude and real choice}

The three questions were averaged to form an attitude score $(\alpha=.91)$. We predicted that social exclusion would increase consumers' preference for the anthropomorphized brand. A 2 (social exclusion: exclusion vs. inclusion) $\times 2$ (anthropomorphism: yes vs. no) ANOVA revealed no significant main effects $(p s>.50)$, but yielded a significant interaction between social exclusion and anthropomorphism $(F(1,114)=5.91$, $p<.05$; see Table 1). Planned contrasts revealed that when the candy was anthropomorphized, excluded participants expressed more favorable attitudes towards the candy $(M=6.80)$ than did included participants $(M=5.87 ; F(1,114)=4.59, p<.05)$. In contrast, when the candy was not anthropomorphized, participants did not differ in their brand attitudes whether they were excluded $(M=5.89)$ or included $(M=6.41 ; p>.20)$. 
Table 1

Key findings from studies $1-3$.

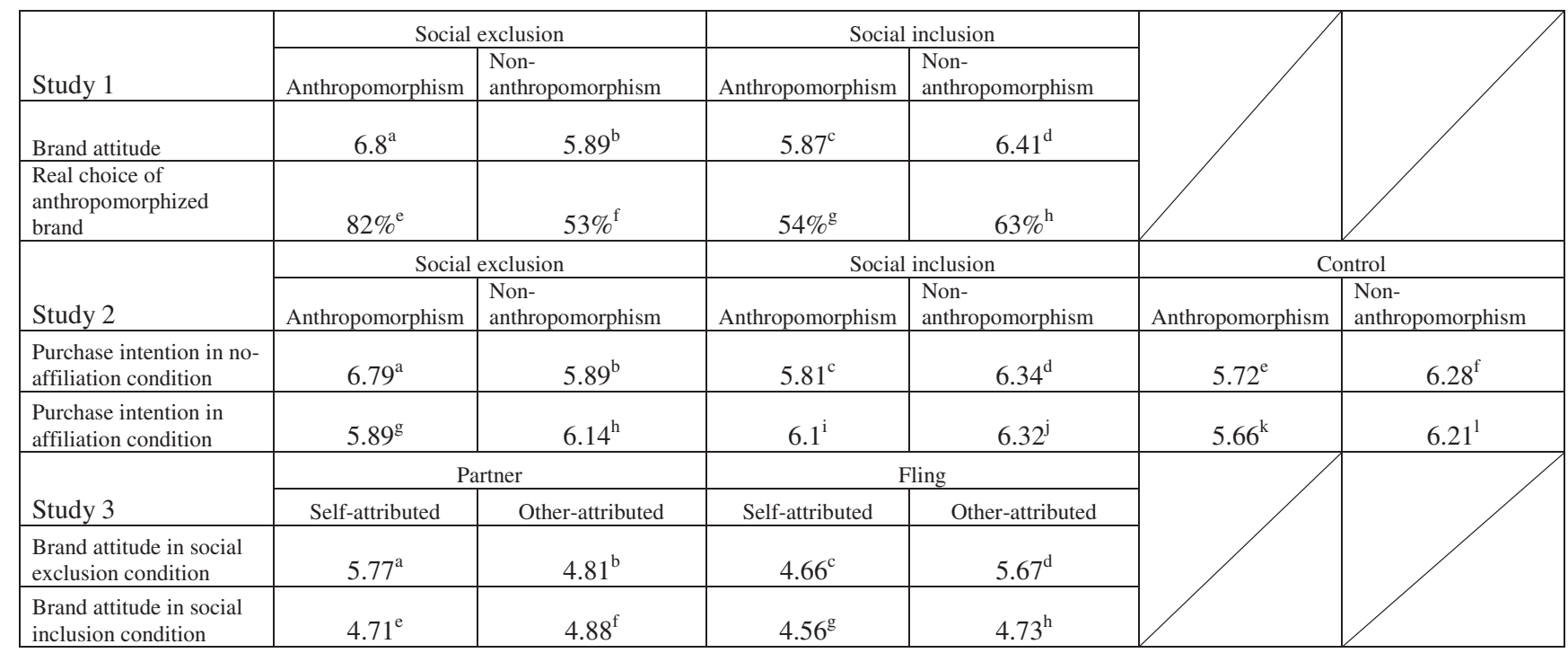

Note: In study 1 , significant contrasts $(p<.05)$ include: ab, ac, ef, eg. Other contrasts are not significant.

In study 2 , significant contrasts $(p<.05)$ include: ab, ac, ae, ag, ak. Other contrasts are not significant.

In study 3 , significant contrasts $(p<.05)$ include: $\mathrm{ab}, \mathrm{ac}, \mathrm{ae}, \mathrm{af}, \mathrm{ag}, \mathrm{ah}, \mathrm{db}, \mathrm{dc}, \mathrm{de}, \mathrm{df}, \mathrm{dg}, \mathrm{dh}$. Other contrasts are not significant.

Moreover, excluded participants showed more favorable attitudes toward M\&M's candy when it was anthropomorphized than non-anthropomorphized $(F(1,114)=4.72$, $p<.05)$. In contrast, socially included participants did not differ in their attitudes towards the candy whether or not it was anthropomorphized $(p>.20)$.

Hypothesis 1 was also supported by examining participants' real choice between M\&M's candy and Skittles candy, using logistic regression. Regressing the choice of candy $(1=$ Choose M\&M; $0=$ Choose Skittles) on social exclusion, anthropomorphism, and their interaction yielded only a significant interaction effect (Wald $\chi^{2}=4.96, p<.05$; see Table 1 ). No other effects were significant $(p>.40)$. Excluded participants were more likely than included participants to choose M\&M's candy when it was anthropomorphized ( $82 \%$ vs. $54 \%$; Wald $\chi 2=4.94, p<.05)$. However, there was no significant effect when M\&M's candy was not anthropomorphized (53\% vs. $63 \% ; p>.40)$. In addition, socially excluded participants were more likely to choose M\&M's candy when it was anthropomorphized than when it was described only as a product (Wald $\chi 2=5.32, p<.05$ ). However, socially included participants' choice share of M\&M's candy did not differ between the anthropomorphism and non-anthropomorphism conditions $(p>.40)$. Note that only M\&M's, and not Skittles, was anthropomorphized in the relevant condition.

\section{Discussion}

Study 1 provided preliminary evidence that social exclusion increases consumer preference for an anthropomorphized brand. Participants who were induced to feel socially excluded (vs. included) indicated more favorable attitudes and were more likely to actually choose a real brand of candy when it was thought of as a person. Although both the attitude measure and real choice in study 1 support hypothesis 1 , it is not clear whether the effects were driven by the social exclusion or inclusion conditions. Thus, we added a control condition in study 2 to examine which condition drives the effect. Moreover, study 2 aims to examine the underlying mechanism using both mediation and moderation approaches.

\section{Study 2}

Study 2 was guided by four major goals. The first goal was to test the robustness of the effect documented in study 1 . To this end, four changes in the procedure were employed. First, instead of using the Cyberball game, we manipulated exclusion versus inclusion by using an online social network scenario in which participants' friend requests either get rejected or accepted (Wan et al., 2014). Second, rather than instructing participants to think about the target brand as a person or an object, we manipulated anthropomorphism by describing the brand using either first-person language (anthropomorphism condition) or third-person language (non-anthropomorphism condition), a method adapted from Aggarwal and McGill (2012). Third, we tested the effect in another product category (i.e., battery). Fourth, we assessed consumer preference by measuring their intentions to purchase the brand.

The second goal of this study was to examine the psychological mechanism underlying the effect of social exclusion on the preference for anthropomorphized brands. Specifically, we tested whether participants' need for social affiliation mediated our effects. We also sought support for our proposed mechanism using a moderation approach (Spencer, Zanna, \& Fong, 2005). If social exclusion enhances preference for an anthropomorphized brand because excluded (vs. non-excluded) consumers have stronger desire for social affiliation, then providing consumers with the opportunity to 
build social relationships with other people prior to the brand evaluation task would fulfill the affiliation need and reduce these consumers' desire to affiliate with an anthropomorphized brand. Therefore, in study 2 we manipulated the opportunity to interact with other participants, and we expect that the effect would be attenuated when participants are offered the opportunity to interact with other participants.

Thirdly, we added a control condition in which neither exclusion nor inclusion was manipulated, which would allow us to test whether social exclusion or inclusion drives the effect on participants' preference for anthropomorphized brand. Lastly, we measured participants' mood and tested whether mood could explain the experimental effect.

\section{Methods and procedure}

Three hundred and forty-two undergraduate students $(27 \%$ male) from a major university in Hong Kong participated in this experiment in return for monetary compensation. They were randomly assigned to a 3 (social exclusion: exclusion vs. inclusion vs. control) $\times 2$ (affiliation opportunity: yes vs. no) $\times$ 2 (anthropomorphism: yes vs. no) between-subjects design. Participants were told that they would be completing several unrelated studies.

\section{Manipulation of social exclusion}

We first manipulated social exclusion versus inclusion using an online social networking scenario adapted from Wan et al. (2014). Participants were asked to imagine that they browsed a new social networking website and found three persons that they were interested in befriending. They sent their personal information, such as personality and hobbies, to the three persons and requested to befriend them. In the social exclusion condition, participants were told that their friend requests were rejected by all three people. In the social inclusion condition, participants were told that their friend requests were accepted by all three people. Participants also described their feelings in detail as if they were experiencing the situation. Participants in the control condition read the same descriptions about the social networking website and wrote down their opinions about the site. Participants then completed the manipulation check questions (i.e. "I felt ignored"; "I felt rejected"; "I felt like an outsider") and reported their mood ("I felt pleasant/happy," $1=$ not at all; $9=$ very much).

\section{Measure of the need for social affiliation and manipulation of affiliation opportunity}

Next, participants in the exclusion and inclusion conditions reported their need for social affiliation on two scales adapted from Williams (2007): I feel a sense of belonging (reversed coded) and I feel disconnected ( $1=$ not at all; $9=$ very much), which served as the mediator.

Participants then proceeded to a task which ostensibly invited them to provide feedback about their university. This task actually manipulated the opportunity for social affiliation. In the condition of "affiliation opportunity," participants were paired with another participant to complete this task in the form of group discussion. The two participants introduced themselves to each other, exchanged opinions about the university, and discussed together suggestions for the university. After a five minute discussion, they returned to their computers and typed down what they had discussed. In the condition of "no-affiliation opportunity", participants completed this task by themselves without discussing it with others. They were given five minutes to think and type down their suggestions to the university. Then all participants proceeded to a brand survey.

\section{Manipulation of anthropomorphism and measure of consumer} preference

In the brand survey, participants were told that a new battery brand would be introduced to the market, and the company would like to know what consumers think about it. Participants read a paragraph describing a battery brand named JK, either in first person language or in third person language (Aggarwal \& McGill, 2007), which served as the manipulation of anthropomorphism. Specifically, participants in the anthropomorphism condition read the following self-introduction: "Hello, my name is JK. I am small but energetic. It's easy for me to keep working tirelessly for months. My family has three brothers including me. My elder brother is taller than me while my younger one is shorter. Bring your favorite one home now! We would be your reliable partners in your daily life". In contrast, participants in the non-anthropomorphism condition read the following product introduction: "JK is a small battery with high power capacity. JK can function continually for months. The JK product line has three battery models, including large, medium and small sizes. Bring your favorite one home now! They would be your reliable batteries in your daily life". After reading the paragraph, participants indicated their intention to purchase JK on a scale of 1 (not at all) to 9 (very much). As the manipulation check of anthropomorphism, participants rated the extent of their agreement with four statements at the end of the study: "JK feels like a person"; "I've been thinking about JK as a person"; "JK has its own personality"; "JK has its own intention" ( 1 = strongly disagree; 9 = strongly agree $)$.

\section{Results and discussion}

\section{Manipulation checks}

We first averaged responses to the three manipulation check questions for social exclusion to form an exclusion score $(\alpha=$ .94). A 3 (social exclusion: exclusion vs. inclusion vs. control) $\times 2$ (affiliation opportunity: yes vs. no) $\times 2$ (anthropomorphism: yes vs. no) ANOVA on this score revealed that participants in the exclusion conditions felt more socially excluded $(M=6.09)$ than did those in the inclusion conditions $(M=2.20, F(1$, $330)=311.62, p<.001)$ and control condition $(M=2.90$, $F(1,330)=207.73, p<.001)$. Additionally, participants in the inclusion condition felt less socially excluded than those in the control condition $(F(1,330)=10.05, p<.01)$. No other effects were significant $(p \mathrm{~s}>.20)$.

We formed an anthropomorphism score by averaging the four manipulation check items $(\alpha=.93)$ and submitted this score 
to the $3 \times 2 \times 2$ ANOVA. Validating our anthropomorphism manipulation, participants in the anthropomorphism condition perceived the battery to be more humanized $(M=5.34)$ than did those in the non-anthropomorphism condition $(M=3.39$; $F(1,330)=97.56, p<.001)$. No other effects were significant $(p \mathrm{~s}>.10)$.

\section{Consumer preference: purchase intention}

We predicted that social exclusion would increase intentions to purchase the anthropomorphized brand, but that this effect would be eliminated when participants had an opportunity to affiliate with another person (H3). Supporting our hypothesis, a 3 (social exclusion: exclusion vs. inclusion vs. control) $\times 2$ (affiliation opportunity: yes vs. no) $\times 2$ (anthropomorphism: yes vs. no) ANOVA on purchase intention yielded a significant three-way interaction $(F(2,330)=3.64, p<.05$; see Table 1$)$. No other effects were significant $(p s>.20)$. Simple contrasts revealed the nature of the interaction. In the no affiliation opportunity conditions, socially excluded participants were more willing to purchase the anthropomorphized brand $(M=6.79)$ than were socially included participants $(M=5.81 ; F(1,330)=$ $6.45, p<.05)$ and those in the control condition $(M=5.72$; $F(1,330)=8.54, p<.01)$. Participants in the inclusion and control conditions did not differ in their purchase intention $(p>.80)$. When the brand was not anthropomorphized, however, participants did not differ in their purchase intentions whether they were in the exclusion $(M=5.89)$, inclusion $(M=6.34)$, or control conditions $(M=6.28 ; p \mathrm{~s}>.20$; see Table 1). Thus, the results in the no affiliation opportunity conditions replicated the findings of study 1 . In contrast, when participants had the opportunity to affiliate with another person before seeing the brand, their purchase intentions did not differ whether the brand was anthropomorphized $\left(M_{\text {exclusion }}=5.89\right.$ vs. $M_{\text {inclusion }}=6.10$ vs. $\left.M_{\text {control }}=5.66 ; p \mathrm{~s}>.20\right)$ or not anthropomorphized $\left(M_{\text {exclusion }}=6.14\right.$ vs. $M_{\text {inclusion }}=6.32$ vs. $M_{\text {control }}=6.21 ; p \mathrm{~s}>.60$; see Table 1$)$.

\section{Mediator: the need for social affiliation}

We predicted that the path from social exclusion to purchase intention should operate through the need for social affiliation, and this should apply only when the brand was anthropomorphized and the participants did not have an affiliation opportunity before seeing the anthropomorphized brand. We thus followed Model 19 of the PROCESS Macro (Hayes, 2012) to test the moderated mediation. Since our predictor variable (i.e., social exclusion) was categorical with three levels, we followed Hayes and Preacher's (2014) approach to conduct two sets of mediation analyses. First, we compared the social exclusion condition with the social inclusion condition while keeping the control condition as a covariate in the analysis. Second, we compared the social exclusion condition with the control condition while keeping the social inclusion condition as a covariate. We found that both sets of analyses yielded significant moderated mediation results. In this study, we focused on the comparison between social exclusion and social inclusion as depicted in Fig. 1. Specifically, we first formed an affiliation need score by averaging participants' responses to the two items that measured need for social affiliation $(r=.57)$ and then conducted the analysis using social exclusion as the independent variable, anthropomorphism and affiliation opportunity as the moderators, need for social affiliation as the mediator, and purchase intention as the dependent variable. The first part of the model (i.e., mediator model) showed that the effect of social exclusion on need for social affiliation was significant $(B=-2.40, S E=.22, t(339)=-11.09, p<.001)$. The second part of the model (i.e., dependent variable model) revealed a significant three-way interaction between need for social affiliation, anthropomorphism and affiliation opportunity $(B=.52$, $S E=.18, t(329)=2.90, p<.001)$. A 5000 resamples bootstrap confirmed that the indirect effect was significant when there was no affiliation opportunity before participants saw the anthropomorphized brand $(95 \%$ bias corrected, $\mathrm{CI}=-1.29$ to -.37$)$. In contrast, when there was an affiliation opportunity before participants saw the anthropomorphized brand, the indirect effect was not significant $(95 \%$ bias corrected, $\mathrm{CI}=-.56$ to .20$)$. When

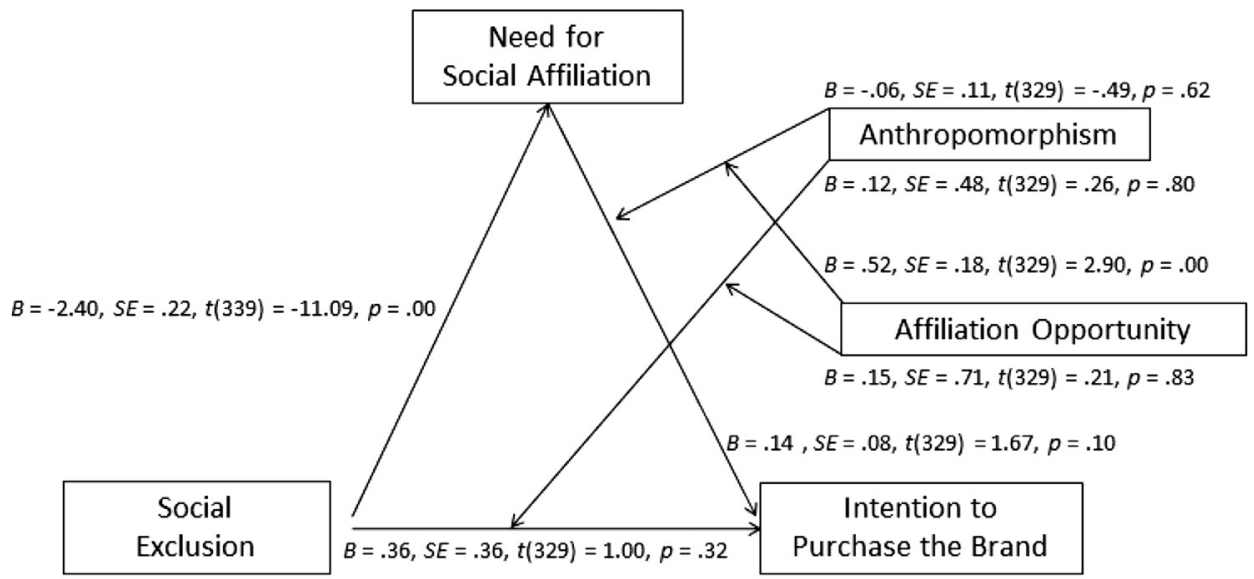

Note:

This analys is compared the social exclusion condition with the social inclusion cond ition (controlling for the control condition).

Indirect effect was significant when there was no affiliation opportunity before participants saw the anthropomorphized brand $(\mathrm{Cl}=-1.29$ to -.37$)$.

Fig. 1. Moderated mediation in study 2. 
the brand was not anthropomorphized, the indirect effect was not significant whether participants had an affiliation opportunity $(95 \%$ bias corrected, $\mathrm{CI}=-.83$ to .09$)$ or did not have one $(95 \%$ bias corrected, $\mathrm{CI}=-.14$ to .75 ). These results confirmed that the effect of social exclusion on purchase intention of the anthropomorphized brand was mediated by the need for social affiliation when there was no affiliation opportunity.

\section{Mood}

We also followed Hayes (2012, model 19) to assess the mediating effect of mood using a 5000 resamples bootstrapping procedure. We found that the bias-corrected confidence interval of the indirect effects through mood included zero ( $95 \%$ bias corrected, $\mathrm{CI}=-.71$ to .53 ), which suggests that mood was unlikely to have driven the effects.

\section{Discussion}

Using both moderation and mediation approaches, study 2 showed that the need for social affiliation was underlying the effect of social exclusion on preference for anthropomorphized brands. Study 2 replicated the finding in study 1 in the condition where participants did not have the opportunity to connect with other people after being socially excluded, and also demonstrated that this effect is eliminated in the condition where participants had an opportunity to actually affiliate with another person following exclusion. This moderation effect was mediated by participants' need for social affiliation. Additionally, the control condition confirmed that the effect was driven by social exclusion rather than social inclusion. Finally, we ruled out mood as an alternative explanation for the effect.

\section{Study 3}

In the previous two studies we demonstrated that socially excluded participants were motivated to restore their affiliation needs, and therefore exhibited greater preference for anthropomorphized brands. Study 3 examines the specific types of brand relationships that socially excluded consumers prefer when affiliating with anthropomorphized brands, depending on their attribution of the cause of social exclusion. Specifically, participants might either blame themselves (self-attributed) or blame others (other-attributed) for their experience of being social excluded. To test the type of brand relationship that excluded consumers would desire, participants were presented with information about a hypothetical anthropomorphized brand that was described as either a partner brand or a fling brand (Fournier, 1998), and indicated their attitude towards the brand. We predicted that participants in the self-attributed exclusion condition would prefer the partner brand, whereas participants in the other-attributed exclusion condition would prefer the fling brand. Finally, study 3 generalizes our findings by testing the effect in a non-student sample and by employing a different manipulation of social exclusion.

\section{Methods and procedure}

Three hundred and seventy-eight participants (39\% male) were recruited from the United States through Amazon's Mechanical Turk in exchange for a small monetary compensation. Eight participants were removed from this study because they failed an instructional manipulation check (Oppenheimer, Meyvis, \& Davidenko, 2009) that requested participants to input a specific word at the end of the study. Participants were randomly assigned to one of the eight conditions in a 2 (social exclusion: exclusion vs. inclusion) $\times 2$ (attribution: self-attributed vs. other-attributed) $\times 2$ (brand role: partner vs. fling) between-subjects design. This study did not involve the non-anthropomorphism conditions, because communicating a brand as either a partner or a fling is essentially anthropomorphizing the brand, and this study focuses on the influence of different attributions of social exclusion on consumer preference for anthropomorphized brands with different roles.

\section{Manipulation of social exclusion attribution}

Participants first performed an experience recall task that manipulated social exclusion attribution (Pickett, Gardner, \& Knowles, 2004). In the self-attributed exclusion condition, participants were asked to recall an experience in which they were excluded by their friends, or family, or someone they care about. Importantly, the cause for their being excluded should be attributed to the self. Participants were instructed to describe the feelings and thoughts of being left alone and the reason why they blamed themselves for what had happened. In contrast, in the other-attributed exclusion condition, participants were asked to recall an exclusion experience in which the cause should be attributed to others. Participants were instructed to describe the feelings and thoughts of being left alone and why they blamed others for what had happened. An independent pretest $(n=53)$ confirmed that participants in the self-attributed exclusion condition blamed the self more than those in the other-attributed exclusion condition $(F(1,51)=18.99, p<.001)$. Participants in the inclusion condition were asked to recall an experience in which they were included by their friends, family, or someone they care about. The reason for being socially included should be attributed to either themselves or others, depending on condition. They were instructed to describe their feelings and thoughts about such an experience. All participants responded to manipulation checks that assessed the extent to which they felt ignored, rejected, and like an outsider, on nine-point scales ( 1 = not at all; $9=$ very much).

\section{Manipulation of brand role}

Next, participants completed a short filler task about space perception, and then proceed to an ostensibly unrelated marketing survey. In this survey, we presented advertising messages of a new sub-brand of shampoo described as either a partner or a fling, and asked participants' opinion for this sub-brand. We used shampoo because Fournier (1998) showed that shampoo brands can be perceived as either a partner or a fling by consumers. 
We ran a series of pretests to develop the brand stimuli. The first pretest $(n=56)$ asked participants to indicate their opinions about several real shampoo brands on seven-point scales. L'Oreal emerged as a brand name that elicited relatively favorable brand attitudes $(M=4.96)$ but was neither strongly associated with a long-term partner nor a short-term fling perception $(M=4.18)$, indicated by the moderate ratings. A review of advertising for L'Oreal confirmed that it is not explicitly described as a partner or a fling brand. This allowed us to manipulate brand role in the laboratory for an ostensibly new sub-brand of L'Oreal's shampoo. A second pretest $(n=56)$ identified "Modi" as a name for the new sub-brand with a moderate likability $(M=3.46)$.

Two advertising messages, described in first person language (Aggarwal \& McGill, 2007), were designed to manipulate the brand role using a method adapted from prior research (Aaker, Fournier, \& Brasel, 2004). Specifically, brand role was manipulated via advertising messages and highlighted taglines. In the partner condition, participants first read the following advertising message: "Hello, I am Modi, a new member of the L'Oreal family. I look like my family members but I am younger than all of them. Bring me home, and I will always be with you". Then they read a tagline which stressed on the partner role: "Together with a Partner like Me, Enjoy Our Life Forever". Participants in the fling condition read the identical advertising message except the last sentence: "Bring me home, and I will be with you tonight," and the tagline which emphasized a fling role: "Try Me, Enjoy Our Moment Tonight". An independent pretest ( $n=45)$ confirmed that the partner (vs. fling) advertising is perceived to communicate a long-term relationship $(F(1$, $43)=9.70, p<.01)$, but liking of the two advertisements did not differ $(F<1)$. After reading the brand advertising, participants indicated their attitude towards the new sub-brand: How much do you like Modi $(1=$ dislike; $9=$ like $)$ ? How good is Modi $(1=$ bad; 9 = good $)$ ? What's your opinion about Modi $(1=$ negative; $9=$ positive $)$ ?

\section{Results and discussion}

\section{Manipulation check}

We first averaged responses to the three manipulation check questions for social exclusion to form an exclusion score $(\alpha=.98)$. A 2 (social exclusion: exclusion vs. inclusion) $\times 2$ (attribution: self-attributed vs. other-attributed) $\times 2$ (brand role: partner vs. fling) ANOVA on this score revealed only a significant effect of social exclusion: participants in the exclusion condition $(M=7.18)$ felt more excluded than those in the inclusion condition $(M=1.94$, $F(1,362)=556.27, p<.001)$. No other effects were significant $(p \mathrm{~s}>.30)$.

\section{Consumer preference: brand attitude}

We first averaged responses to the three items to form a brand attitude score $(\alpha=.95)$. We predicted that self-attributed exclusion would increase preference for a partner brand whereas other-attributed exclusion would increase preference for a fling brand. This hypothesis was supported by a 2 (social exclusion: exclusion vs. inclusion) $\times 2$ (attribution: self-attributed vs. other-attributed) $\times 2$ (brand role: partner vs. fling) ANOVA on the brand attitude measure. The main effect of social exclusion was significant $(F(1,362)=7.57, p<.01)$, consistent with the results of studies 1 and 2 that social exclusion increased consumers' preference for anthropomorphized brands. The main effects of attribution and brand role were not significant $(p>.40)$. Importantly, the three-way interaction was significant $(F(1,362)=7.27, p<.01$; see Table 1). Simple contrasts revealed an enhanced preference for the partner brand among the self-attributed excluded participants: participants who were excluded and attributed the reason to themselves were more favorable toward the partner brand $(M=5.77)$ than excluded participants who blamed others for exclusion $(M=4.81 ; F(1$, $362)=7.11, p<.01)$. In contrast, socially included participants' attitudes towards partner brand did not differ whether they attributed the reason to self $(M=4.71)$ or other $(M=4.88$; $F<1$ ). Moreover, participants in the other-attributed condition reported more favorable attitudes toward fling brand $(M=5.67)$ than did participants in the self-attributed exclusion condition $(M=4.66 ; \quad F(1,362)=7.86, p<.01)$. However, attitudes towards the fling brand did not differ among socially included participants who attributed the reason to self $(M=4.56)$ or other $(M=4.73 ; F<1)$. These results demonstrate an enhanced preference for a fling brand among other-attributed excluded participants.

Additionally, we found that participants who blamed themselves for being socially excluded showed greater preference for the partner brand (vs. fling brand; $F(1,362)=9.40, p<.01$ ), whereas participants who blamed other for being socially excluded exhibited more favorable attitude towards the fling brand (vs. partner brand; $F(1,362)=5.76, p<.05$ ). In contrast, socially included participants' preference for the partner brand and fling brand did not differ whether they attributed the reason to self or other $\left(F_{\mathrm{S}}<1\right)$.

\section{Discussion}

Building on the first two studies showing that social exclusion increased consumer preference for anthropomorphized brands, study 3 demonstrates that socially excluded consumers differed in their preference for anthropomorphized brands that play different roles, depending on their attribution of social exclusion. Participants who blamed themselves for being socially excluded preferred a partner brand whereas those who blamed others preferred a fling brand. The preference for brands did not differ when participants were socially included.

\section{General discussion}

The current research proposes that social exclusion increases consumers' preference for anthropomorphized brands. This effect occurs because being socially excluded heightens people's need for social affiliation, motivating them to turn to anthropomorphized brands for social affiliation. We further hypothesize that socially excluded consumers would prefer different types of relationships with an anthropomorphized brand (partner vs. fling), depending on their causal attribution for being socially excluded. 
Three experiments provided convergent evidence for these propositions. Compared with non-excluded participants, socially excluded participants both reported more favorable attitudes toward and actually chose more anthropomorphized M\&M's candy (study 1), and indicated greater willingness to buy an anthropomorphized battery (study 2). These effects were robust whether social exclusion was manipulated with a Cyberball game (study 1) or a social networking scenario (study 2), whether brand anthropomorphism was varied by using first person language (study 2) or by inducing anthropomorphic thinking (study 1), and whether the brands were real (study 1) or hypothetical (study 2). In addition, study 2 revealed that this effect was mediated by the need for social affiliation and was attenuated when excluded participants had the opportunity to affiliate with other participants before seeing the anthropomorphized brand. Furthermore, study 3 showed that excluded consumers who blamed themselves increased their preference for partner brands, whereas excluded consumers who blamed others showed greater preference for fling brands.

\section{Theoretical contributions}

The current research contributes to a number of different literatures, including social exclusion, compensatory consumption, anthropomorphism, and consumer-brand relationships. First, this work provides the first systematic investigation of consumers' preference for anthropomorphized brands as a function of their motivation to seek affiliation directly with a product or brand. The bulk of past research on social exclusion has examined how experiencing social exclusion influences individuals' behavior in their interactions with other people (Maner et al., 2007; Williams et al., 2000) and consumers' product choice as a medium of building social connections with other people. For example, in Mead et al.'s (2011) studies, products were used as the instrument to socially connect with other people. The current research demonstrates that social exclusion can prompt consumers to seek affiliation with products directly. That is, the brand, rather than other people, becomes the social affiliation target. Excluded consumers seek to affiliate with anthropomorphized brands which demonstrate human-like characteristics, especially when they did not have an opportunity to first affiliate with other people.

The present research also adds to a growing body of compensatory consumption research which demonstrates that social motivations guide consumption decisions (Mandel, Rucker, Levav, \& Galinsky, 2016; Rucker \& Galinsky, 2008). For example, Dubois, Rucker, and Galinsky (2012) found that feeling powerless motivates consumers to prefer supersized food and drinks, because larger options are status-signaling and can fulfill the need for status. Our work details how consumers compensate for deficiencies of belongingness by affiliating with brands in which consumers can see human-like characteristics. These findings are consistent with prior findings that excluded consumers have a compensatory desire for renewed social affiliation (Maner et al., 2007), but we go beyond this by documenting the specific type of brands that can help compensate for the relational desire.

Moreover, our studies advance research on anthropomorphism by identifying additional conditions that impact the effectiveness of employing anthropomorphism in marketing, an area still in its infancy. Pioneering research showed that characteristics of products, such as feature fit to human schema (Aggarwal \& McGill, 2007) and product appearance design (Landwehr et al., 2011), influence the effectiveness of anthropomorphism in marketing. Extending prior research, our work suggests that the effect of anthropomorphism is contingent on both consumers' psychological state of belongingness (i.e., being excluded or included) and the role that the brand plays in the consumer-brand relationship (i.e., partner or fling).

Finally, the current research extends the literature on consumer-brand relationships by adding new insights about how consumers form relationships with brands in similar ways to building relationships with people. We find that consumers thirsty for social relationships are interested in affiliating with brands that play particular roles. Fournier (1998) introduced a variety of brand roles including partner and fling. Prior research has mainly focused on partner brands (Aggarwal \& McGill, 2012; Fournier \& Alvarez, 2012), and fling brands have received relatively little attention (Alvarez \& Fournier, 2012). Our findings suggest that long-term committed partnerships may not be the only favorable type of relationship that consumers desire to form with their brands. For other-blaming excluded consumers who do not expect committed relationships. it is more appealing to embrace a fling brand which offers short-term rewards.

\section{Practical implications}

Findings from the current research also provide implications for marketing and advertising managers. Primarily, managers should consider the psychological state of the target consumers when employing anthropomorphism in marketing communications. In today's digital economy, analysis of consumers' activities from online and mobile social network will enable marketers to understand consumers' psychological states better (Moe \& Schweidel, 2014). For example, new immigrants, people who suffer setbacks in romantic relationships, and employees who complain about workplace ostracism are consumers who may feel socially excluded. When targeting these consumers, marketers could promote their brands and products in an anthropomorphic manner. Alternatively, when a brand has already established an anthropomorphized image, marketers may induce the feeling of social exclusion in the advertisement and then introduce the brand. Moreover, marketers may use different brand stories in advertisings to specify the type of brand that would be particularly appealing to excluded consumers, depending on whether consumers explicitly blame themselves or others for being socially excluded. 


\section{Limitations and future research}

The current research offers several potential avenues for future work. First, we demonstrate that excluded consumers are motivated to re-affiliate with anthropomorphized brands directly. A further question is whether excluded consumers would prefer a brand that serves as a medium for affiliating with human beings or an anthropomorphized brand that can be seen as an affiliation target itself, when both options are presented. One factor could be consumers' assessment of their chances of success in reconnecting with other human beings. When excluded consumers expect to have a high chance (vs. low chance) of building positive connections with the target person, they may prefer brands that can allow them to re-affiliate with another person. Another possible factor is the visibility of consumption. In a public context (vs. private context), excluded consumers may be more likely to use the brand as an instrument to signal their desire for social relationships. Future research may delineate the specific conditions for these effects.

Our research uncovers a motivational account such that socially excluded consumers are motivated to seek social affiliation and consequently prefer anthropomorphized brands. It would be interesting to examine to what extent one's affective responses might also contribute to this effect. Although we found in our study that participants' general mood did not account for the effect, future research may explore whether some specific types of feelings can be triggered by the brands, which might influence the consumption preference of socially excluded consumers.

Another question is to what extent consumers' relationship building with anthropomorphized brands is conscious versus non-conscious. Prior work suggests that anthropomorphism is an automatic psychological process, and that individuals may not be consciously aware that they respond to anthropomorphized non-human entities in social ways (Chartrand, Fitzsimons, \& Fitzsimons, 2008). Therefore, we speculate that the effect of social exclusion on consumer preference for anthropomorphized brands might be automatic. Future research that systematically tests this prediction could broaden our understanding of consumers' relationship-building with brands. On a related note, future research can explore additional types of relationships that excluded consumers may prefer, such as secret affairs and enslavements (Fournier, 1998). Future research might also examine when consumers may withdraw from anthropomorphized brands; for example, Puzakova, Kwak, and Rocereto (2013) demonstrated that consumers are more likely to blame the brand for wrongdoings when it is anthropomorphized than non-anthropomorphized. Therefore, we suspect that one possibility is that consumers may be more likely to withdraw from an anthropomorphized brand during a brand crisis.

Another avenue for future research is the consumers' tendency to anthropomorphize brands. Epley et al. (2007) suggested that loneliness is a key driver of anthropomorphism, which implies that feeling socially excluded may increase individuals' tendency to anthropomorphize brands. The current research builds on Epley et al. (2007)'s work, by manipulating anthropomorphism and leading participants by design to either anthropomorphize a brand or not. Future research may examine how social disconnection influences consumers' tendency to anthropomorphize brands without explicitly instructing them to do so.

Lastly, though social inclusion was not the focus of the current research, we find that social inclusion neither enhances nor decreases consumer preference for anthropomorphized brands. Although Waytz and Epley (2012) showed that being socially connected to close others increases the tendency to dehumanize more socially distant others, we find that socially included consumers did not differ from consumers in the control condition in their attitudes towards the anthropomorphized brand, which echoes prior research showing that socially included consumers' need for compensatory resources is similar to that of those in a control condition (e.g., Duclos, Wan, \& Jiang, 2013). We speculate that this is because consumers who have been socially included would not decline the opportunity to enjoy a positive experience, although their motivation to actively seek social affiliation is not that strong. Future research may nonetheless examine the theoretical nuances of social inclusion, and explore when and why inclusion may influence consumer preference for anthropomorphized brands.

\section{Appendix A. Supplementary data}

Supplementary data to this article can be found online at http://dx.doi.org/10.1016/j.jcps.2016.05.004.

\section{References}

Aaker, J., Fournier, S., \& Brasel, S. A. (2004). When good brands do bad. Journal of Consumer Research, 31(1), 1-16.

Aggarwal, P., \& McGill, A. L. (2007). Is that car smiling at me? Schema congruity as a basis for evaluating anthropomorphized products. Journal of Consumer Research, 34(4), 468-479.

Aggarwal, P., \& McGill, A. L. (2012). When brands seem human, do humans act like brands? Automatic behavioral priming effects of brand anthropomorphism. Journal of Consumer Research, 39(2), 307-323.

Alvarez, C., \& Fournier, S. (2012). Brand flings: When great brand relationships are not made to last. In S. Fournier, M. Breazeale, \& M. Fetscherin (Eds.), Consumer-Brand Relationships: Theory and Practice. London: Routledge/Taylor \& Francis.

Bartholomew, K., \& Horowitz, L. M. (1991). Attachment styles among young adults: A test of a four-category model. Journal of Personality and Social Psychology, 61(2), 226-244.

Baumeister, R. F., DeWall, C. N., Ciarocco, N. J., \& Twenge, J. M. (2005). Social exclusion impairs self-regulation. Journal of Personality and Social Psychology, 88(4), 589-604.

Chartrand, T. L., Fitzsimons, G. M., \& Fitzsimons, G. J. (2008). Automatic effects of anthropomorphized objects on behavior. Social Cognition, 26(2), 198-209.

Collins, N., \& Read, S. J. (1990). Adult attachment, working models, and relationship quality in dating couples. Journal of Personality and Social Psychology, 58(4), 644-663.

DeWall, C. N., Maner, J. K., \& Rouby, D. A. (2009). Social exclusion and early-stage interpersonal perception: Selective attention to signs of acceptance. Journal of Personality and Social Psychology, 96(4), 729-741.

Dubois, D., Rucker, D. D., \& Galinsky, A. D. (2012). Super size me: Product size as a signal of status. Journal of Consumer Research, 38(6), 1047-1062. 
Duclos, R., Wan, E. W., \& Jiang, Y. (2013). Show me the honey! Effects of social exclusion on financial risk-taking. Journal of Consumer Research, 40(1), $122-135$.

Epley, N., Akalis, S., Waytz, A., \& Cacioppo, J. T. (2008). Creating social connection through inferential reproduction loneliness and perceived agency in gadgets, gods, and greyhounds. Psychological Science, 19(2), 114-120.

Epley, N., Waytz, A., \& Cacioppo, J. T. (2007). On seeing human: A three-factor theory of anthropomorphism. Psychological Review, 114(4), 864-886.

Fournier, S. (1998). Consumers and their brands: Developing relationship theory in consumer research. Journal of Consumer Research, 24(4), 343-353.

Fournier, S., \& Alvarez, C. (2012). Brands as relationship partners: Warmth, competence, and in-between. Journal of Consumer Psychology, 22(2), $177-185$.

Gardner, W. L., Pickett, C. L., Jefferis, V., \& Knowles, M. (2005). On the outside looking in: Loneliness and social monitoring. Personality and Social Psychology Bulletin, 31(11), 1549-1560.

Hayes, A. F. (2012). PROCESS: A versatile computational tool for observed variable mediation, moderation, and conditional process modeling. White Paper. http://www.afhayes.com/introduction-to-mediation-moderationandconditional-process-analysis.html\#process

Hayes, A. F., \& Preacher, K. J. (2014). Statistical mediation analysis with a multicategorical independent variable. British Journal of Mathematical and Statistical Psychology, 67(3), 451-470.

Kim, S., \& McGill, A. L. (2011). Gaming with Mr. Slot or gaming the slot machine? Power, anthropomorphism, and risk perception. Journal of Consumer Research, 38(1), 94-107.

Landwehr, J. R., McGill, A. L., \& Herrmann, A. (2011). It's got the look: The effect of friendly and aggressive 'facial' expressions on product liking and sales. Journal of Marketing, 75(3), 132-146.

Maner, J. K., DeWall, C. N., Baumeister, R. F., \& Schaller, M. (2007). Does social exclusion motivate interpersonal reconnection? Resolving the "porcupine problem". Journal of Personality and Social Psychology, 92(1), 42-55.

Mandel, N., Rucker, D. D., Levav, J., \& Galinsky, A. D. (2016). The Compensatory Consumer Behavior Model: How Self-Discrepancies Drive Consumer Behavior, Journal of Consumer Psychology.

Mead, N. L., Baumeister, R. F., Stillman, T. F., Rawn, C. D., \& Vohs, K. D. (2011). Social exclusion causes people to spend and consume strategically in the service of affiliation. Journal of Consumer Research, 37(5), 902-919.

Moe, W. W., \& Schweidel, D. A. (2014). Social media intelligence. Cambridge University Press

Oppenheimer, D. M., Meyvis, T., \& Davidenko, N. (2009). Instructional manipulation checks: Detecting satisficing to increase statistical power. Journal of Experimental Social Psychology, 45(4), 867-872.
Pickett, C. L., Gardner, W. L., \& Knowles, M. (2004). Getting a cue: The need to belong and enhanced sensitivity to social cues. Personality and Social Psychology Bulletin, 30(9), 1095-1107.

Puzakova, M., Kwak, H., \& Rocereto, J. F. (2013). When humanizing brands goes wrong: The detrimental effect of brand anthropomorphization amid product wrongdoings. Journal of Marketing, 77(3), 81-100.

Rotter, J. B. (1966). Generalized expectancies for internal versus external control of reinforcement. Psychological Monographs, 80(1), 1-28.

Rucker, D. D., \& Galinsky, A. D. (2008). Desire to acquire: Powerlessness and compensatory consumption. Journal of Consumer Research, 35(August), $257-267$.

Schmitt, D. P. (2005). Is short-term mating the maladaptive result of insecure attachment? A test of competing evolutionary perspectives. Personality and Social Psychology Bulletin, 31(6), 747-768.

Siegel, J. M. (1990). Stressful life events and use of physician services among the elderly: The moderating role of pet ownership. Journal of Personality and Social Psychology, 58(6), 1081-1086.

Spencer, S. J., Zanna, M. P., \& Fong, G. T. (2005). Establishing a causal chain: Why experiments are often more effective than mediational analyses in examining psychological processes. Journal of Personality and Social Psychology, 89(6), 845-851.

Swaminathan, V., Stilley, K. M., \& Ahluwalia, R. (2009). When brand personality matters: The moderating role of attachment styles. Journal of Consumer Research, 35(6), 985-1002.

Twenge, J. M., Baumeister, R. F., Tice, D. M., \& Stucke, T. S. (2001). If you can't join them, beat them: Effects of social exclusion on aggressive behavior. Journal of Personality and Social Psychology, 81(6), 1058-1069.

Wan, E., Xu, J., \& Ding, Y. (2014). To be or not to be unique? The effect of social exclusion on consumer choice. Journal of Consumer Research, 40(6), 1109-1122.

Waytz, A., \& Epley, N. (2012). Social connection enables dehumanization. Journal of Experimental Social Psychology, 48(1), 70-76.

Weiner, B. (1985). An attributional theory of achievement motivation and emotion. Psychological Review, 92(4), 548-573.

Williams, K. D. (2007). Ostracism. Annual Review of Psychology, 58(January), 425-452.

Williams, K. D., Cheung, C. K., \& Choi, W. (2000). Cyberostracism: effects of being ignored over the Internet. Journal of personality and social psychology, 79(5), 748-762.

Williams, K. D., \& Jarvis, B. (2006). Cyberball: A program for use in research on interpersonal ostracism and acceptance. Behavior Research Methods, 38(1), 174-180. 